\title{
KANDUNGAN AIR PADA SEGMEN DAUN TANAMAN \\ PADI (Oryza sativa L.) LOKAL SULAWESI UTARA SAAT KEKERINGAN YANG DIINDUKSI DENGAN POLIETILEN GLIKOL 8000
}

\author{
Risa Junita Mereh ${ }^{1)}$, Nio Song Ai ${ }^{1}$, Parluhutan Siahaan ${ }^{1)}$ \\ ${ }^{1)}$ Program Studi Biologi, FMIPA Universitas Sam Ratulangi Manado \\ e-mail : ryunita_11@yahoo.com; niosongai@unsrat.ac.id; luhut.siahaan68@unsrat.ac.id
}

\begin{abstract}
ABSTRAK
Penelitian ini telah dilakukan untuk mengkaji kandungan air sebagai respon fisiologi pada segmen daun tanaman padi lokal Sulut (varietas Temo, Ombong, Burungan, dan Superwin) terhadap kekeringan yang diinduksi dengan PEG 8000 secara in vitro. Segmen daun padi dipotong-potong $1 \mathrm{~cm} \times 1 \mathrm{~cm}$ dan diberi tiga macam perlakuan PEG 8000 (dengan potensial air/PA medium 0; $0,25$; dan - $0,5 \mathrm{MPa})$, dan empat waktu pengambilan sampel $(0,4,8$ dan 12 jam) dalam tiga kali ulangan. Hasil penelitian menunjukkan bahwa bahwa faktor varietas, faktor waktu perlakuan, faktor konsentrasi PEG 8000, dan interaksi antara ketiga faktor tersebut tidak menyebabkan perbedaan kandungan air segmen daun yang nyata.
\end{abstract}

Kata kunci: Cekaman kekeringan, PEG 8000, Potensial air, Segmen daun

\section{LEAF WATER CONTENT IN LEAF SEGMENTS OF NORTH SULAWESI LOCAL RICE (Oryza sativa L.) UNDER POLYETHYLENE-GLYCOL- 8000-INDUCED DROUGHT}

\begin{abstract}
A study was conducted to evaluate leaf water content as one of physiological responses in leaf segments of North Sulawesi local rice (cv. Temo, Ombong, Burungan, and Superwin) under PEG 8000 - induced-drought. The rice leaves were cut into $1 \mathrm{~cm}$ x $1 \mathrm{~cm}$ segments and treated with PEG 8000 solutions (medium water potential or PA of $0 ;-0.25$; and $-0.5 \mathrm{MPa}$ ), four sampling times $(0$, 4,8 and 12 hours) and 3 replicates. The results indicated that factors of varieties, treatment period, concentration of PEG 8000, and interaction among these factors did not result in any differences in water content of rice leaf segments.
\end{abstract}

Keywords: Drought stress, PEG 8000, Water potential, Leaf segment

\section{PENDAHULUAN}

Kekeringan merupakan ancaman yang paling sering mengganggu sistem dan produksi pertanian di Indonesia terutama yang berkaitan dengan tanaman pangan (Hadiyanto, 2007). Padi merupakan sumber pangan bagi $95 \%$ penduduk Indonesia. Konsumsi beras penduduk Indonesia lebih dari dua kali lipat rata-rata konsumsi beras dunia, yaitu sebesar $139 \mathrm{~kg}$ per tahun (Setiawan et al., 2016).

Indonesia menghadapi tantangan besar dalam mencukupi kebutuhan pangan. Seiring peningkatan jumlah penduduk, kebutuhan pangan semakin meningkat (Abidin, 2015). Selama kurun waktu 37 tahun Indonesia masih belum dapat memenuhi kebutuhan konsumsi beras total, sehingga pemerintah masih mengimpor beras (Hessie, 2009). Perubahan iklim menjadi salah satu penyebab terjadinya kekeringan yang dapat menurunkan kualitas dan kuantitas produksi padi, terutama varietas padi yang sensitif terhadap kekeringan (Tao et al. 2006). Bencana kekeringan di Indonesia pada bulan September 2013 menyebabkan lebih dari 2 juta jiwa korban mengalami kelaparan dan bencana kekeringan juga membuat lebih dari 1 juta hektar areal persawahan hampir tidak produktif (BNPB 2013). Respon tanaman terhadap kekeringan adalah penurunan laju pertumbuhan daun, penurunan ukuran sel, dan peningkatan efisiensi penggunaan air (Richard et al. 2002). 
Potensi Sulawesi Utara (Sulut) sebagai pusat pengembangan padi cukup besar dalam meningkatkan produksi pangan (Dinas Pertanian dan Peternakan Sulawesi Utara, 2011). Oleh sebab itu informasi tentang sifat tahan kering maupun tahan terhadap cekaman abiotik lainnya pada padi varietas lokal Sulawesi Utara (Superwin Ombong, Burungan, dan Temo) diperlukan dalam upaya untuk memenuhi kebutuhan pangan.

Penelitian ini bertujuan untuk mengevaluasi kandungan air daun, sebagai respon fisiologi segmen daun tanaman padi lokal Sulawesi Utara (varietas Temo, Ombong, Burungan, dan Superwin) terhadap kekeringan yang diinduksi dengan PEG 8000 secara in vitro.

\section{BAHAN DAN METODE}

\section{Tempat dan waktu Penelitan}

Penelitian dilaksanakan selama lima minggu di rumah kaca di Jl. Arnold Mononutu Kota Manado, Sulawesi Utara dan dilanjutkan selama tiga minggu di Laboratorium Ekologi Jurusan Biologi FMIPA Universitas Sam Ratulangi.

\section{Seleksi Benih}

Seleksi benih dilakukan dengan cara meredam benih dengan air garam selama 2-3 Jam dengan tujuan untuk mendapatkan kualitas benih yang baik. Benih disterilisasikan dengan menggunakan Bayclin® 2\% selama 2-3 menit sebanyak tiga kali, kemudian benih dicuci dengan air masak sebanyak tiga kali kemudian benih tersebut direndam dalam air selama 1 x 24 jam. Sebelum penanaman tiap pot yang telah berisi $500 \mathrm{~g}$ tanah taman disiram dengan air sampai kapasitas lapang dan dipelihara sampai tahap empat daun yang berkembang penuh (modifikasi dari Nio dan Ludong, 2013)

\section{Pemeliharaan Tanaman}

Benih ditanam pada media tanam dalam pot botol plastik bervolume $600 \mathrm{~mL}$. Pada tiap pot ditanam 3 benih yang telah berkecambah, kemudian disiram dengan campuran air dan pupuk (6 g pupuk GandasilD dalam $10 \mathrm{~L}$ air) sampai kapasitas lapang setiap dua hari. Setelah tanaman mencapai tahap empat daun yang berkembang penuh (4 fully expanded leaf), dipilih satu tanaman dalam tiap pot untuk selanjutnya digunakan dalam penelitian (modifikasi Nio dan Ludong, 2013).

\section{Persiapan Sampel Daun sebelum Perlakuan}

Sampel daun dipetik dan dicuci dengan larutan $\mathrm{CaSO}_{4}$ 0,5 mM, kemudian daun dipotong-potong menjadi segmen daun berukuran $1 \mathrm{~cm} \times 1 \mathrm{~cm}$ dan direndam dalam medium basal. Medium basal yang digunakan ialah larutan Nutrisi Hidroponik AB Mix Minimax®. Segmen daun diadaptasikan selama 1 x 24 jam dalam medium basal dan disinari cahaya lampu cool white 36 watt 2880 lumen selama 12 jam (modifikasi Nio et al., 2011).

\section{Perlakuan Kekeringan dengan PEG 8000}

Segmen daun ditempatkan dalam gelas plastik bervolume $200 \mathrm{~mL}$ yang berisi $100 \mathrm{~mL}$ larutan hidroponik Mix A dan B yang ditambahkan dengan larutan PEG 8000, sehingga terdapat tiga macam medium dengan potensial air (PA) $0 ;-0,25$; dan $-0,5$ MPa. Larutan PEG 0; -0,25; dan -0,5 MPa dibuat dengan cara menambahkan berturutturut 0,135 , dan $198 \mathrm{~g}$ PEG 8000 ke dalam 1 L larutan hidroponik Mix A dan B. Semua gelas plastik diletakkan pada shaker (50 opm) pada suhu $25^{\circ} \mathrm{C}$ dan ditutup dengan plastik cling wrap pada bagian mulut gelas. Sampel daun diambil pada waktu tertentu seperti pada Tabel 1 (modifikasi Nio et al., 2011).

Tabel 1. Waktu pengambilan sampel daun dari larutan PEG $8000(\checkmark)$

\begin{tabular}{lllll}
\hline PEG & Jam & & & \\
\cline { 2 - 5 } (MPa) & 0 & 4 & 8 & 12 \\
\hline 0 & $\checkmark$ & $\checkmark$ & $\checkmark$ & $\checkmark$ \\
$-0,25$ & & $\checkmark$ & $\checkmark$ & $\checkmark$ \\
$-0,5$ & & $\checkmark$ & $\checkmark$ & $\checkmark$ \\
\hline
\end{tabular}

\section{Pengambilan data}

Semua potongan daun dari tiap perlakuan ditimbang berat basahnya (BS) sebelum diletakkan dalam oven kering pada suhu $70^{\circ} \mathrm{C}$ selama 48 jam dan selanjutnya ditimbang berat keringnya (BK) Kandungan air daun atau $\mathrm{KA}$ (mL/g berat kering) ditentukan dengan rumus : KA $(\mathrm{mL} / \mathrm{g}$ berat 
kering $)=(\mathrm{BS}-\mathrm{BK}) / \mathrm{BK} \quad($ Nio et al., 2011; Koda et al., 2017).

\section{HASIL DAN PEMBAHASAN}

Air adalah salah satu komponen yang sangat vital bagi tanaman dan dibutuhkan dalam jumlah yang besar untuk pertumbuhan dan perkembangan tanaman. Sekitar $85-90 \%$ dari berat segar sel-sel dan jaringan tanaman adalah air (Maynard dan Orcott, 1987; Palit, 2015). Kekeringan dalam periode tertentu dapat mengakibatkan penurunan potensial air daun, kandungan air daun, dan kandungan air daun relatif (Bramasto et al., 2015 dalam Koda et al., 2017). Analisis varian untuk
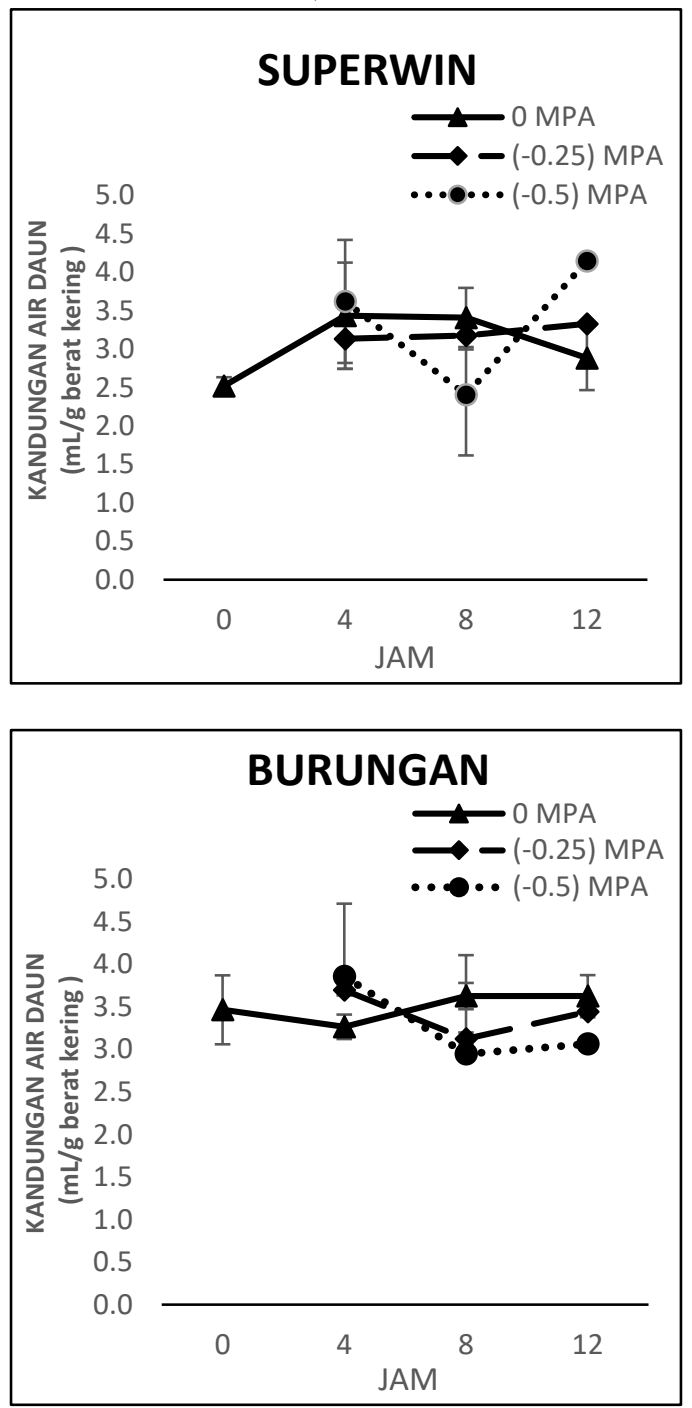

kandungan air daun pada padi varietas Superwin, Ombong, Burungan dan Temo yang diberikan perlakuan cekaman kekeringan dengan induksi PEG 8000 dalam penelitian ini menunjukkan bahwa faktor varietas, faktor waktu perlakuan, faktor konsentrasi PEG 8000, interaksi antara faktor varietas dan waktu perlakuan, interaksi antara faktor varietas dan konsentrasi PEG 8000, interaksi antara faktor waktu perlakuan dan konsentrasi PEG 8000, interaksi antara faktor varietas, waktu perlakuan dan konsentrasi PEG 8000 tidak menyebabkan perbedaan kandungan air daun yang nyata (Gambar 1).
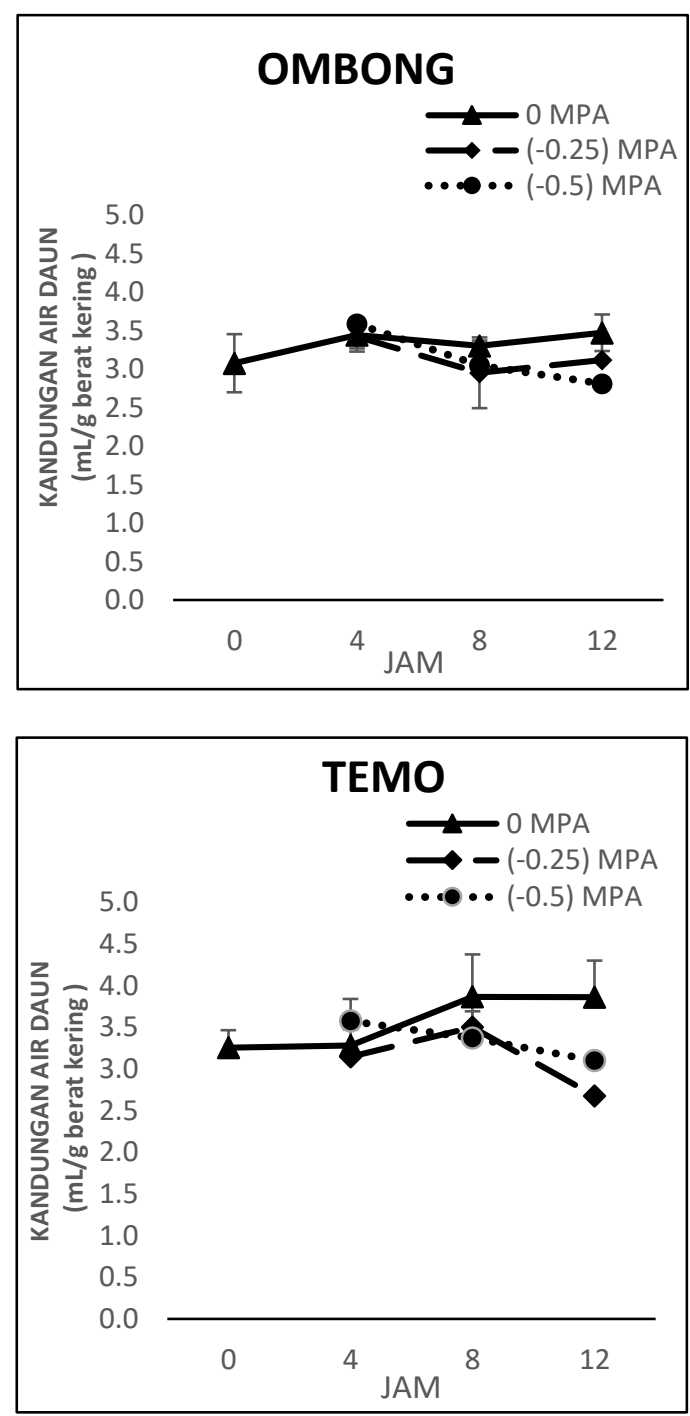

Gambar 1. Kandungan air daun (mL/g berat kering ) pada segmen daun padi lokal Sulut (Superwin, Ombong, Burungan, Temo) setelah perlakuan cekaman kekeringan yang diinduksi dengan PEG 8000 (PA 0, -0,25 dan -0,5 MPa) pada jam ke-0, 4, 8 dan 12 
Hasil penelitian ini berbeda dengan yang dilaporkan oleh Koda et al. (2017), yaitu kandungan air daun pada padi varietas Superwin, Burungan Temo, dan Ombong yang tidak diairi selama 14 hari lebih rendah daripada yang diairi sampai kapasitas lapang. Palupi et al. (2008) juga melaporkan bahwa cekaman kekeringan pada beberapa genotipe bibit kelapa sawit (Elaeis guineensis Jacq.) selama 4 minggu. menyebabkan kandungan air daun pada tanaman yang

disirami sampai 25\% kapasitas lapang lebih rendah daripada yang disirami sampai $100 \%$ kapasitas lapang.

Perbedaan hasil ini disebabkan karena cekaman kekeringan dalam penelitian ini diinduksi dengan PEG 8000, bukan tidak diairi sampai kapasitas lapang. Di samping itu waktu pengamatan yang dilakukan dalam penelitian ini hanya 12 jam dengan rentang waktu yang pendek yaitu setiap 4 jam. Cekaman kekeringan diberikan pada segmen daun dan bukan pada tanaman utuh seperti pada dua penelitian terdahulu.

\section{KESIMPULAN}

Kandungan air daun pada segmen daun padi lokal Sulut (Superwin, Ombong, Burungan dan Temo tidak berbeda nyata antar varietas, waktu perlakuan, konsentrasi PEG 8000, dan interaksi antara ketiga faktor tersebut. Oleh sebab itu kandungan air daun tidak dapat dijadikan sebagai indikator respons fisiologis pada segmen daun padi lokal Sulawesi Utara pada saat kekeringan yang diinduksi oleh PEG 8000.

\section{DAFTAR PUSTAKA}

BNPB. 2013. Laporan Pusdalops BNPB, Jakarta.

Hadiyanto, S. 2007. Pola Tingkat Kerawanan Kekeringan di Jawa Tengah. Tesis.
Hessie, R. 2009. Analisis Produksi Padi dan konsumsi Beras dalam negeri serta implikasinya terhadap swasembada Beras di Indonesia. Departemen Ekonomi Sumberdaya dan Lingkungan Fakultas Ekonomi danManajemen, Institut Pertanian Bogor.

Koda, M, Nio, S.A. dan P.S. Siahaan. 2017. Kandungan Air Daun Padi Lokal Sulut pada Fase Vegetatif Saat Mengalami Rendaman dan Kekurangan Air. Jurnal Bios Logos 7(1):22-26.

Nio, S.A., T.D. Colmer, L.J. Wade and G. Cawthray. 2011. Osmotic Adjustment and Solutes Accumulation in Leaves of Wheat (Triticum aestivum L.) During water deficit. Journal of Mathematics and Sciences. 16:43-48.

Nio, S.A., and D.P.M. Ludong. 2013. Comparing the Drought Tolerance of Locarice Cultifar Superwin with Other Cultifar in Nort Sulawesi Province Based Ondry Matter Partitioning. 4th International Converence of Global Resource Conservation: Brawijaya University.

Setiawan, A., W. Abbas, Z., Yaktiworo I. 2016. Perilaku Konsumen dalam Pembelian Beras Organik Produksi Kabupaten Pringsewu. 4(2) : 192-193.

Sujinah dan A. Jamil. 2016. Mekanisme Respon Tanaman Padi Terhadap Cekaman Kekeringan dan Varietas Toleran. Balai Besar Penelitian Tanaman Padi. Subang. 11:1.

Tao, H., H. Brueck, K. Dittert, C. Kreye, S. Lin, and B. Sattelmacher. 2006. Growth and yield formation for rice (Oryza sativa L.) in the water-saving ground cover rice production system (GCRPS). Field Crops Research 95(1):1-12. 